\title{
TAXONOMIC STUDY AND PARTIAL CHARACTERIZATION OF ANTIMICROBIAL COMPOUNDS FROM A MODERATELY HALOPHILIC STRAIN OF THE GENUS ACTINOALLOTEICHUS
}

\author{
Farida Boudjelal $^{1}$; Abdelghani Zitouni ${ }^{1}$; Florence Mathieu ${ }^{2}$; Ahmed Lebrihi' ${ }^{2}$ Nasserdine Sabaou $^{{ }^{*}}$
}

${ }^{1}$ Laboratoire de Recherche sur les Produits Bioactifs et la Valorisation de la Biomasse, Ecole Normale Supérieure de Kouba, BP

92, 16050 Kouba, Alger, Algérie; ${ }^{2}$ Université de Toulouse, Laboratoire de Génie Chimique UMR 5503 (CNRS/INPT/UPS), ENSAT/INP de Toulouse, 1 avenue de l'Agrobiopôle, Castanet-Tolosan Cedex, France.

Submitted: May 01, 2010; Returned to authors for corrections: September 29, 2010; Approved: January 31, 2011.

\begin{abstract}
A moderately halophilic actinomycete strain designated AH97 was isolated from a saline Saharan soil, and selected for its antimicrobial activities against bacteria and fungi. The AH97 strain was identified by morphological, chemotaxonomic and phylogenetic analyses to the genus Actinoalloteichus. Analysis of the 16S rDNA sequence of strain AH97 showed a similarity level ranging between $95.8 \%$ and $98.4 \%$ within Actinoalloteichus species, with A. hymeniacidonis the most closely related. The comparison of the physiological characteristics of AH97 with those of known species of Actinoalloteichus showed significant differences. Strain AH97 showed an antibacterial and antifungal activity against broad spectrum of microorganisms known to be human and plant pathogens. The bioactive compounds were extracted from the filtrate culture with $n$-butanol and purified using thin layer chromatography and high pressure liquid chromatography procedures. Two active products were isolated, one hydrophilic fraction (F1) and another hydrophobic (F2). Ultraviolet-visible, infrared, mass and ${ }^{1} \mathrm{H}$ and ${ }^{13} \mathrm{C}$ nuclear magnetic resonance spectroscopy studies suggested that these molecules were the dioctyl phthalate (F2) and an aminoglycosidic compound (F1).
\end{abstract}

Key words: Actinoalloteichus, taxonomy, biological activities, structure, dioctyl phthalate

\section{INTRODUCTION}

Actinomycetes are the most significant group of microorganisms considered as an important producer of antibiotics and other important bioactive substances (4). The filamentous Actinomycetales species produces over 10000 bioactive compounds. The most frequent producers, the
Streptomyces species, produce 7600 compounds (74\% of all Actinomycetales), while other actinomycetes represent $26 \%$, altogether 2500 compounds (2). These organisms produce perhaps the most diverse and most unique, unprecedented, sometimes very complicated compounds exhibiting excellent antibacterial potency and usually low toxicity (2).

In the course of screening for new bioactive compounds, 
several research studies are currently oriented towards isolation of rare actinomycetes from different ecosystems (13). The isolation of these microorganisms that produce bioactive compounds is of great interest in the development of new molecules to fight against many pathogens especially with the emergence of antibiotic multi-resistance pathogenic bacteria.

Halophilic and salt-tolerant actinomycetes are extremophilic microorganisms, which are used by several research programs around the world to isolate new natural compounds (4).

In fact, our laboratory takes a particular interest in extreme environment, like saline soils and their microflora. The ecological distribution of actinomycetes from Saharan soils has been studied in Algeria and their biodiversity in those arid soils has been demonstrated (23).

During a screening programme of the search for new antibiotics from non-Streptomyces genera, new molecules were obtained $(12,32,33)$. As part of this program, we identified a new halophilic actinomycete (strain AH97) having interesting antimicrobial activity, which assigned to the genus Actinoalloteichus.

In present study, we describe the polyphasic taxonomic characterization of actinomycete strain AH97 isolated from an Algerian Saharan soil having antimicrobial activity against various bacteria and fungi. The production, extraction, purification and partial characterization of active molecules of this strain are reported as well.

\section{MATERIALS AND METHODS}

\section{Origin of actinomycete}

The strain AH97 was isolated from a Saharan soil collected in Tamanrasset (Hoggar, south of Algeria; latitude, $22^{\circ} 49^{\prime} \mathrm{N}$; longitude, $5^{\circ} 28^{\prime} \mathrm{E}$ ).

\section{Microbial strains and culture conditions}

The strain AH97 was grown at $30^{\circ} \mathrm{C}$ in tryptic soy broth
(TSB) (contents per liter: $17.0 \mathrm{~g}$ tryptose; $3.0 \mathrm{~g}$ soytone; $5.0 \mathrm{~g}$ $\mathrm{NaCl} ; 15 \mathrm{~g}$ agar) fortified with $5 \% \mathrm{NaCl}$. The $\mathrm{pH}$ was adjusted to 7.3 prior to autoclaving.

For antibacterial and antifungal experiments, Bacillus subtilis ATCC 6633 and Mucor ramannianus NRRL1829 (sensitive strains) were used as the indicator microorganisms.

\section{Taxonomic study}

Cultural characteristics of strain AH97 were studied on yeast extract-malt extract agar (ISP2) (27), inorganic saltsstarch agar (ISP4) (27), tryptic soy agar (TSA) (27) and complex medium agar (CMA) (26). All media were supplemented with $5 \%$ of $\mathrm{NaCl}$. Colors of aerial and substrate mycelia were determined with the ISCC-NBS centroid color charts (National Bureau of Standards, USA 1964). The micromorphology of strain AH97 was examined under light microscopy for the mycelial organization and sporulation.

For the physiological study, fifty nine tests were considered, including the utilization of 20 carbohydrate compounds, the degradation of adenine, guanine, xanthine, hypoxanthine, milk casein, tyrosine, testosterone (6), tween 80, gelatine, starch, esculin and arbutin (20), the decarboxylation of nine organic acids (7) and the production of nitrate reductase (20). The strain AH97 was checked for salt requirement or tolerance by inoculation on TSA containing $0,5,7,10,15$ and $20 \%$ of $\mathrm{NaCl}$, as described by Kushner (11). The strain was also examined for its ability to grow on TSA (with $5 \%$ of $\mathrm{NaCl}$ ), supplemented with 6 antibiotics or with lysozyme (8) and to grow at $\mathrm{pH} 5$ and 9 , and at $42^{\circ} \mathrm{C}$.

For the chemotaxonomic analysis, biomass was obtained from culture grown on shake TSB medium supplemented with $5 \%$ of $\mathrm{NaCl}$, and incubated at $30^{\circ} \mathrm{C}$ for 7 days. Diaminopimelic acid (DAP) isomer, whole-cell sugars pattern and phospholipids were analysed according to the methods of Becker et al. (1), Lechevalier and Lechevalier (14) and Minnikin et al. (21), respectively. 
DNA preparation, PCR amplification and sequence analysis

DNA was prepared according to the method of Liu et al. (18). The strain AH97 was grown at $30^{\circ} \mathrm{C}$ for 7 days in a shake flask containing $100 \mathrm{~mL}$ of TSB medium supplemented with $5 \%$ of $\mathrm{NaCl}$. PCR amplification of the $16 \mathrm{~S}$ rDNA of the halophilic strain was performed using two primers: $27 \mathrm{f}\left(5^{\prime}-\right.$ AGTTTGATCCTGGCTCAG-3') and 1492r (5'GGTTACCTTGTTACGACTT-3'). The 16S rDNA was amplified by PCR using Invitrogen kit. The final volume of reaction mixture of $50 \mu \mathrm{L}$ contained $1 \mathrm{X}$ PCR buffer $(10 \mathrm{mmol}$ of Tris- $\mathrm{HCl}, 50 \mathrm{mmol}$ of $\mathrm{KCl}, \mathrm{pH} 9.0$ at $25^{\circ} \mathrm{C}$ ), $1.5 \mathrm{mmol}$ of $\mathrm{MgCl}_{2}, 200 \mathrm{mmol}$ of each dNTP, $1 \mathrm{mmol}$ of each primer, 1.25 $\mathrm{U}$ of Taq DNA polymerase and $1 \mu \mathrm{L}(500 \mathrm{ng})$ of the purified DNA. The amplification was performed on a STRATAGENE RoboCycler Gradient 96, according to the following profile: an initial denaturation step at $98^{\circ} \mathrm{C}$ for $3 \mathrm{~min}$, after which Taq polymerase was added, followed by 30 amplification cycles of $94^{\circ} \mathrm{C}$ for $1 \mathrm{~min}, 52^{\circ} \mathrm{C}$ for $1 \mathrm{~min}$, and $72^{\circ} \mathrm{C}$ for $2 \mathrm{~min}$ and a final extension step of $72^{\circ} \mathrm{C}$ for $10 \mathrm{~min}$. The PCR product was detected by agarose gel electrophoresis and was visualized by ultraviolet fluorescence after ethidium bromide staining.

The sequencing reaction was performed by MilleGen Company (Toulouse, France). The same primers as before and an automated sequencer were used for this purpose. The obtained sequences were compared for similarity level with the reference species of bacteria contained in genomic database banks, using the 'NCBI Blast' available at http://www.ncbi.nlm.nih.gov/

\section{Phylogenetic analysis}

Phylogenetic and molecular evolutionary analyses were conducted using softwares included in MEGA version 3.0 package (10). The $16 \mathrm{~S}$ rDNA sequence of the strain AH97 was aligned using the CLUSTAL W program (30) against corresponding nucleotide sequences of Actinoalloteichus reference species retrieved from GenBank. Evolutionary distance matrices were generated as described by Jukes and Cantor (9) and a phylogenetic tree was inferred by the neighbor-joining method (24). Tree topologies were evaluated by bootstrap analysis (5) based on 1000 resamplings of the neighbor-joining dataset.

\section{Antimicrobial activity of the strain AH97}

The antimicrobial spectrum was determined by conventional agar method (agar cylinders method). The microorganisms used are listed in Table 2.

Strain AH97 was grown on TSA agar plates supplemented with $5 \%$ of $\mathrm{NaCl}$ for 7 days at $30^{\circ} \mathrm{C}$, then calibrated agar cylinders ( $5 \mathrm{~mm}$ in diameter) were cut out and placed onto the agar surface (nutrient agar or Sabouraud agar, covered respectively by $10 \mathrm{~mL}$ of culture containing $10^{5} \mathrm{CFU} \mathrm{mL}^{-1}$ for bacteria or $10^{4} \mathrm{CFU} \mathrm{mL} \mathrm{m}^{-1}$ for fungi). A sterile cylinder of TSA supplemented with $5 \%$ of $\mathrm{NaCl}$ was used as control. The plates were incubated at $30^{\circ} \mathrm{C}$ for $24-48 \mathrm{~h}$ after a diffusion process for $4 \mathrm{~h}$ at $4^{\circ} \mathrm{C}$. The diameters of any inhibition zones formed around the cylinder of actinomycete isolate were then measured.

\section{Kinetic of growth and production of antimicrobial compounds}

For the pre-culture, the strain AH97 was grown on TSA supplemented with $5 \%$ of $\mathrm{NaCl}$, for 7 days at $30^{\circ} \mathrm{C}$. The mycelium was scraped and inoculated into a $250 \mathrm{~mL}$ Erlenmeyer flask containing $50 \mathrm{~mL}$ of TSB supplemented with $5 \%$ of $\mathrm{NaCl}$. Aliquots $(5 \%, \mathrm{v} / \mathrm{v})$ of this pre-culture were transferred into 500-mL Erlenmeyer flasks containing $100 \mathrm{~mL}$ of the same medium. The cultures were incubated on a rotary shaker $(250 \mathrm{rpm})$ at $30^{\circ} \mathrm{C}$ for 7 days. The antibacterial and antifungal activities were assayed daily against Bacillus subtilis and Mucor ramannianus by the agar diffusion method (well technique). Each well of $10 \mathrm{~mm}$ in diameter was filled with 0.2 $\mathrm{mL}$ of the supernatant. The growth (dry weight of mycelium) was determined (22) and the $\mathrm{pH}$ was measured. 


\section{Production and extraction of antimicrobial compounds}

For the production of active compounds, fermentations were carried out in $500 \mathrm{~mL}$ Erlenmeyer flasks containing 100 $\mathrm{mL}$ of TSB supplemented with $5 \%$ of $\mathrm{NaCl}\left(250 \mathrm{rpm}, 30^{\circ} \mathrm{C}\right.$ and 3 days).

The culture broth $(10 \mathrm{~L})$ was centrifuged at $5,000 \times g$ for $10 \mathrm{~min}$ to remove the biomass. The cell-free supernatant was extracted with an equal volume of $n$-butanol. The organic extract was concentrated to dryness, recuperated in methanol and bioassayed against $B$. subtilis and $M$. ramannianus by paper disk diffusion method.

\section{Biological and chemical detection of antimicrobial compounds}

Crude extract samples were subsequently subjected to thin-layer chromatography (TLC). Samples were spotted onto $20 \times 20-\mathrm{cm}^{2}$ silica gel plates (Merck Art 5735, kieselgel 60F254), and then developed with $n$-butanol-acetic acid-water (B.A.W.) (3: 1: 1, v/v) as the solvent mixture. The active spot was detected by bioautography (3) on silica gel plates seeded with M. ramannianus or B. subtilis. Clear halos, due to growth inhibition of the microorganisms, indicated the location of antimicrobial compounds on the TLC plates, and the retention factor (Rf) values were recorded. The antimicrobial compounds were also detected under ultraviolet irradiations at 254 and 365 $\mathrm{nm}$ and by spraying with some chemical reagents such as napthoresorcinol- $\mathrm{H}_{2} \mathrm{SO}_{4}$ and ninhydrin.

\section{Purification of antimicrobial compounds}

Concentrated extracts were purified on preparative TLC silica gel plates (Merck $60 \mathrm{~F}-254 ; 0.5 \mathrm{~mm}$ thick). The plates were developed with B.A.W. solvent system (3: 1: 1, v/v), and then air dried. The active band was visualized in ultraviolet light at 254 and $365 \mathrm{~nm}$, scraped from the plates, eluted with methanol and concentrated using the Rotavapor. The antibiotic activity of the band against B. subtilis and M. ramannianus was measured by the paper disk method. Final purification of the antimicrobial compounds was carried out by a high- performance liquid chromatography (HPLC) (Waters, Milford, MA, USA) system equipped in first step (in order to separate the hydrophilic fraction of the hydrophobic fraction) with a C18 column (Uptisphere UP5ODB, $250 \times 7.8 \mathrm{~mm}$; Interchim) and in second step with a C18 pyramid column (Nucleodur VP 250/10, $250 \times 10 \mathrm{~mm}$; Machery Nagel). The analysis conditions were as follows: a mobile phase with a continuous gradient (convex curve) solvent system from 0 to $100 \%$ methanol in water $(30 \mathrm{~min})$ to separate the active fractions with Uptisphere UP5ODB C18 column, then 80 to $100 \%$ methanol in water $(30 \mathrm{~min})$ to purify the hydrophobic active fraction with the same column, and $100 \%$ water (isocratic) $(30 \mathrm{~min})$ to purify the hydrophilic active fraction with $\mathrm{C} 18$ pyramid column; flow rate of $2 \mathrm{~mL} \mathrm{~min}^{-1}$ and UV detection at $220 \mathrm{~nm}$. The final purification was achieved after the third re-injection in HPLC system.

\section{Spectroscopic studies of antimicrobial compounds}

The UV absorption spectra of the hydrophilic fraction F1 in distilled water and hydrophobic fraction F2 in methanol were determined with a Shimadzu UV 1605 spectrophotometer. Mass spectrum of fraction F1 was recorded on an ion-trap mass spectrometer (Finnigan MAT, San Jose, CA), equipped with a nanospray ion electro-spray ionisation (ESI) source (positif ion mode) and fraction F2 with electron impact by using Nermag R-10-10C spectrometer. Infrared (IR) spectrq of the fractions (F1) and (F2) were obtained with a Perkin Elmer FT-IR 1760 spectrometer. ${ }^{1} \mathrm{H}$ and ${ }^{13} \mathrm{C}$ nuclear magnetic resonance spectra of the hydrophobic compound F2 (in $\mathrm{MeOD}$ ) and hydrophilic compound $\mathrm{F} 1$ (in $\mathrm{D}_{2} \mathrm{O}$ ) were recorded on a Bruker AMX 400 spectrometer operating at 500 MHz.

\section{RESULTS AND DISCUSSION}

\section{Taxonomy}

The strain AH97 grew well on TSA and CMA (7 days at $30^{\circ} \mathrm{C}$ ) supplemented with $5 \%$ of $\mathrm{NaCl}$. The isolate had a 
greenish blue to grayish blue (TSA) or pale yellowish (CMA) aerial mycelium. The substrate mycelium was light yellow on the two media used. Brown to black diffusible pigment was observed on TSA. No growth was observed on ISP2 and ISP4 media with $5 \%$ of $\mathrm{NaCl}$. The aerial mycelium was branched and fragment into straight spore chains after 10 days of incubation at $30^{\circ} \mathrm{C}$. Endospores, sclerotia, sporangia, synnemata and whirls were not observed.

Cell-wall hydrolysate of strain AH97 contained the DLdiaminopimelic acid isomer but glycine was not found. Galactose, mannose and glucose were the characteristic sugars of the whole-cell extract in addition to ribose. Thus, strain AH97 had cell-wall of type III and sugar pattern type C (14). The phospholipid profile was of type PII, characterized by the presence of phosphatidylethanolamine as major phospholipid (15). Based on the morphological and chemical characteristics, AH97 is classified in the genus Actinoalloteichus (19). The genus currently comprises only three species, A. cyanogriseus $\mathrm{IFO} 4455^{\mathrm{T}}$ (29), A. spitiensis DSM44848 ${ }^{\mathrm{T}}$ (28) and $A$. hymeniacidonis $\mathrm{HPA}_{177^{\mathrm{T}}}(29)$, and no one is halophilic.

\section{Physiological characteristics}

The physiological properties of strain AH97 are shown in Table 1. Optimal growth of strain was observed at $30^{\circ} \mathrm{C}$ at $\mathrm{pH}$ 7 and in presence of $\mathrm{NaCl}$ in range 5 to $7 \%$. Strain was unable to grow at concentration 0 and $10 \%$ of $\mathrm{NaCl}$, at $\mathrm{pH} 5$ and at $42^{\circ} \mathrm{C}$, and able to grow at $\mathrm{pH} 9$.

The strain was able to hydrolyse a great number of compounds such as adenine, arbutin, casein, esculin, gelatine, starch, testosterone, tween 80, arabinose, cellobiose, fructose, galactose, glucose, mannitol, rhamnose, ribose, sucrose, trehalose, sodium propionate, sodium pyruvate and sodium succinate but did not utilize guanine, hypoxanthine, tyrosine, xanthine, adonitol, inositol, maltose, mannose, melibiose, raffinose, salicine, sorbitol, xylose, sodium acetate, sodium benzoate, sodium butyrate, sodium citrate, sodium oxalate, sodium tartrate, alanine, proline and serine. It reduced nitrate and was resistant to novobiocin $\left(5 \mu \mathrm{g} \mathrm{mL}^{-1}\right)$, streptomycin $(10$ UI) and vancomycin $\left(30 \mu \mathrm{g} \mathrm{mL} \mathrm{mL}^{-1}\right)$ and sensitive to chloramphenicol (30 $\left.\mu \mathrm{g} \mathrm{mL} \mathrm{mL}^{-1}\right)$, erythromycin (15 UI) and lysozyme $(0.005 \%)$.

Table 1. Physiological characters of strain AH97.

\begin{tabular}{|c|c|c|c|}
\hline Tests & $\begin{array}{l}\text { Strain } \\
\text { AH } 97\end{array}$ & Tests & $\begin{array}{l}\text { Strain } \\
\text { AH97 }\end{array}$ \\
\hline \multicolumn{4}{|l|}{ Degradation of : } \\
\hline Gelatine & + & Decarboxylation of sodium salts: & \\
\hline Guanine & - & Acetate & - \\
\hline Hypoxanthine & - & Benzoate & - \\
\hline Starch & + & Butyrate & - \\
\hline Testosterone & + & Citrate & - \\
\hline Tween 80 & + & Oxalate & - \\
\hline Tyrosine & - & Propionate & + \\
\hline \multirow{2}{*}{ Xanthine } & - & Pyruvate & + \\
\hline & & Succinate & + \\
\hline $\begin{array}{l}\text { Carbon source } \\
\text { utilization: }\end{array}$ & & Tartrate & - \\
\hline Adonitol & - & & \\
\hline Arabinose & + & Nitrate reductase & + \\
\hline Cellobiose & + & & \\
\hline Fructose & + & Growth in the presence of $\mathrm{NaCl}(\%)$ : & \\
\hline Galactose & + & 0 & - \\
\hline Glucose & + & 5 & + \\
\hline Inositol & - & 7 & + \\
\hline Maltose & - & 10 & - \\
\hline Mannitol & + & & \\
\hline Mannose & - & Sensitivity to: & \\
\hline Melibiose & - & Lysozyme $(0.005 \% \mathrm{w} / \mathrm{v})$ & $\mathrm{S}$ \\
\hline Raffinose & - & Chloramphenicol $\left(30 \mu \mathrm{g} \mathrm{mL}^{-1}\right)$ & $\mathrm{S}$ \\
\hline Rhamnose & + & Erythromycin (15 UI) & $\mathrm{S}$ \\
\hline Ribose & + & Novobiocin $\left(5 \mu \mathrm{g} \mathrm{mL}^{-1}\right)$ & $\mathrm{R}$ \\
\hline Salicine & - & Streptomycin (10 UI) & $\mathrm{R}$ \\
\hline Sorbitol & - & Vancomycine $\left(30 \mu \mathrm{g} \mathrm{mL}^{-1}\right)$ & $\mathrm{R}$ \\
\hline Sucrose & + & & \\
\hline Trehalose & + & Growth at: & \\
\hline \multirow[t]{2}{*}{ Xylose } & - & $\mathrm{pH} 5$ & - \\
\hline & & $\mathrm{pH} 7$ and 9 & + \\
\hline $\begin{array}{l}\text { Nitrogen source } \\
\text { utilization: }\end{array}$ & & $42^{\circ} \mathrm{C}$ & - \\
\hline Alanine & - & & \\
\hline Proline & - & Optimal growth temperature & $30^{\circ} \mathrm{C}$ \\
\hline Serine & - & & \\
\hline
\end{tabular}




\section{Phylogenetic analysis}

The 16S rDNA sequences of the strain AH97 (1248 nucleotides) was determined and deposited in GenBank under the accession number FJ379336. This strain was first analysed by a BLAST search and was aligned with those of Actinoalloteichus reference species available in the GenBank database, which confirmed its identification at the genus level. The position of strain AH97 in the $16 \mathrm{~S}$ rDNA Actinoalloteichus tree is shown in Fig. 1

The neighbor-joining tree indicated that the novel strain fall into one distinct clade with the type strains of Actinoalloteichus spitiensis $\quad \mathrm{DSM}_{44848^{\mathrm{T}}} \quad$ (96.2\%), $\quad$ A. cyanogriseus IFO14455 ${ }^{\mathrm{T}}(95.8 \%)$, which were different from strain AH97 (similarity level < 97\%), and A. hymeniacidonis HPA $177^{\mathrm{T}}(98.4 \%)$, the most closely related species. The results suggest that our strain represent a distinct phylogenetic line.

Strain AH97 differed from A. hymeniacidonis (31) by many characters. By contrast to our strain, A. hymeniacidonis was not halophilic, grew well on ISP2, had a brownishpurplish-grey aerial mycelium and a brownish-black substrate mycelium, was able to degrade maltose, mannose, sorbitol, xylose and sodium citrate, unable to degrade arabinose and sodium succinate and reduction of nitrate is negative.

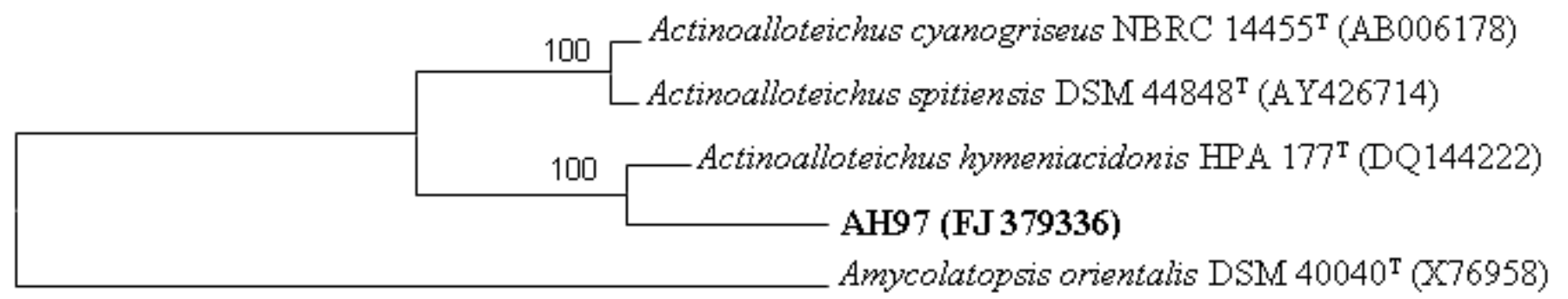

\subsection{5}

Figure 1. Neighbor-joining tree based on $16 \mathrm{~S}$ rDNA sequences showing the relations between the moderately halophilic actinomycete isolate AH97 and type species of the genus Actinoalloteichus. The accession numbers of strain sequences are given in parentheses.

The numbers at the nodes indicate the levels of bootstrap support based on neighbor-joining analyses of 1000 resampled datasets; only values over $50 \%$ are given. Bar: 0.005 nucleotide substitution per nucleotide position. Amycolatopsis orientalis is given as out group.

\section{Antimicrobial activity on solid media}

Strain AH97 showed a broad spectrum of antimicrobial activity (Table 2). It was strongly active against Gram-positive bacteria such as Bacillus coagulans, $B$. subtilis and Staphylococcus aureus and against fungi such as Aspergillus alliaceus, A. carbonarius, A. flavus, A. ochraceus, Mucor ramannianus and Penicillium glabrum. It was moderately active against Enterococcus faecalis, Klebsiella pneumoniae, Salmonella enterica, Serratia marcescens, Kluyveromyces lactis, Saccharomyces cerevisiae and Aspergillus niger. However, no activity was observed against Pseudomonas aeruginosa, $P$. syringae, Agrobacterium tumefaciens, Candida albicans and Botrytis cinerea. 
Table 2. Antimicrobial activity of strain AH97 against various microorganisms.

\begin{tabular}{|c|c|}
\hline Bioassay organisms & $\begin{array}{c}\text { Diameter of inhibition } \\
\text { zone (mm) }\end{array}$ \\
\hline \multicolumn{2}{|l|}{ Gram-positive bacteria } \\
\hline Bacillus coagulans & 30 \\
\hline Bacillus subtilis ATCC 6633 & 30 \\
\hline Enterococcus faecalis & 17 \\
\hline Staphylococcus aureus CIP 7625 & 25 \\
\hline \multicolumn{2}{|l|}{ Gram-negative bacteria } \\
\hline Klebsiella pneumoniae & 14 \\
\hline Salmonella enterica & 18 \\
\hline Serratia marcescens & 13 \\
\hline \multicolumn{2}{|l|}{ Yeasts } \\
\hline Kluyveromyces lactis & 13 \\
\hline Saccharomyces cerevisiae & 18 \\
\hline \multicolumn{2}{|l|}{ Filamentous fungi } \\
\hline Aspergillus alliaceus & 24 \\
\hline Aspergillus carbonarius M333 & 23 \\
\hline Aspergillus flavus & 20 \\
\hline Aspergillus niger & 15 \\
\hline Aspergillus ochraceus & 25 \\
\hline Mucor ramannianus NRRL 1829 & 30 \\
\hline Penicillium glabrum & 20 \\
\hline
\end{tabular}

* Activity was performed using agar cylinder method.

The diameter of the cylinder agar does not include in diameters of inhibition zones.

The strain AH97 is non-active against Agrobacterium tumefaciens $\mathrm{n}^{\circ} 2410$, Pseudomonas aeruginosa, P. syringae $\mathrm{n}^{\circ} 2410$, Candida albicans and Botrytis cinerea.

\section{Growth kinetics and production of antimicrobial compounds}

In TSB medium with $5 \%$ of $\mathrm{NaCl}$, the biomass increased and reached the maximum at 3 days, followed by a stationary phase until 4 days, than decreased. The antifungal activity was detected at 1 day after inoculation and reached a maximum at 3 days. The antibacterial activity began and reached a maximum at 2 days of fermentation than decrease after this. The $\mathrm{pH}$ varied between 7.2 and 8.6 during the incubation (Fig. 2).

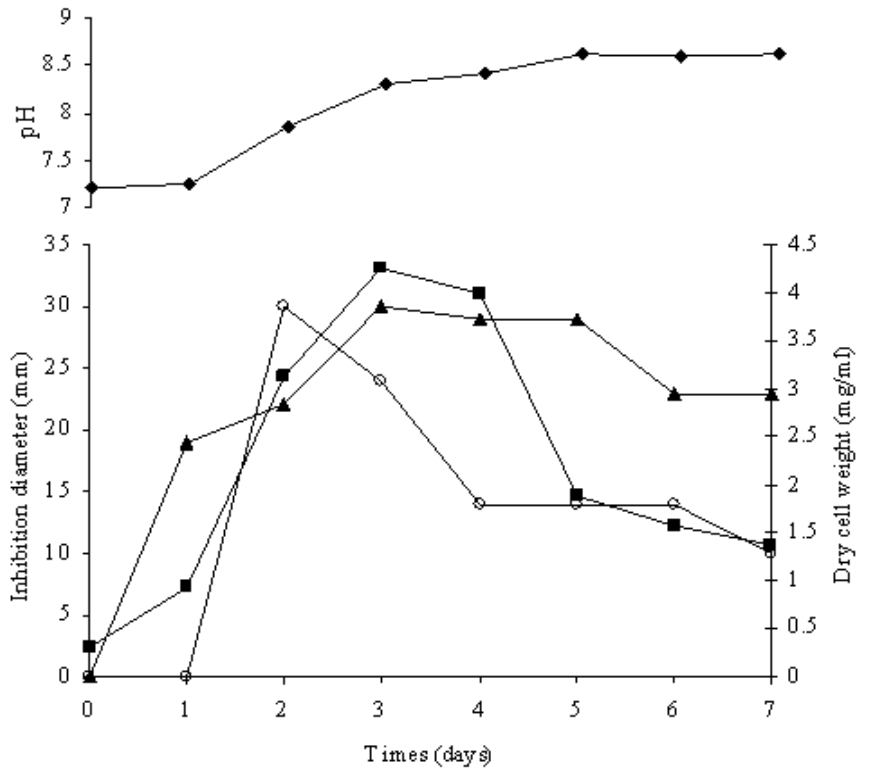

Figure 2. Time course of growth and antibiotic production in TSB medium with $5 \%$ of $\mathrm{NaCl}$ : (ם) dry cell weight, (O) antibacterial activity against Bacillus subtilis, ( $\boldsymbol{\Delta})$ antifungal activity against Mucor ramannianus, $(\downarrow) \mathrm{pH}$.

Inhibition diameter values were measured without diameter of well $(10 \mathrm{~mm})$.

\section{Extraction, purification and partial characterization of antimicrobial compounds}

Various separation steps were applied to $10 \mathrm{~L}$ culture broth of strain AH97 grown in TSB medium supplemented with $5 \%$ of $\mathrm{NaCl}$.

Antimicrobial compounds were extracted from broth culture with $n$-butanol. The active extract was concentrated to dryness using the Rotavapor, recuperated in methanol and analysed by TLC developed in B.A.W. solvent system. One active band, named fraction TM2, was detected by bioautography (at a $\mathrm{Rf}$ value of 0.44 ), which was active against B. subtilis and M. ramannianus.

The active band was scraped from the plates, eluted with methanol, concentrated and purified by HPLC in first with a C18 column (Uptisphere UP5ODB). The chromatogram of the first round of HPLC injection showed two main peaks with 
antibacterial and antifungal activity, which were designated F1 (retention time: RT, $5.00 \mathrm{~min}$, hydrophilic and colorless fraction), and F2 (RT, $17.00 \mathrm{~min}$, hydrophobic and colorless oil). Each fraction was collected separately and re-injected in HPLC system with a C18 pyramid column (Nucleodur) to purified $\mathrm{F} 1$ with $100 \% \mathrm{H}_{2} \mathrm{O}$ eluted phase and $\mathrm{C} 18$ column (Uptisphere UP5ODB) to purified F2 with 80 to $100 \%$ methanol in water eluted phase.

\section{Fraction 1 (F1)}

Chromogenic reactions with napthoresorcinol- $\mathrm{H}_{2} \mathrm{SO}_{4}$ and ninhydrin were positive (presence of sugar and amine). The $\mathrm{UV}$-visible spectrum in water (data not shown) of the pure product exhibited a maximum at $200 \mathrm{~nm}$ in water. The IR absorption spectrum (data not shown) exhibited the following bands: $3390 \mathrm{~cm}^{-1}(\mathrm{O}-\mathrm{H}), 2933$ and $673 \mathrm{~cm}^{-1}(\mathrm{C}-\mathrm{H}), 1675 \mathrm{~cm}^{-1}$
$(\mathrm{C}-\mathrm{OH})$ and $1543 \mathrm{~cm}^{-1}\left(\mathrm{NH}_{2}\right)$. The PM of the fraction F1 (data not shown) is 850 with fragments at m/z 685 and 522. The fragmentation of the majority peak in positive mode showed differences between the ions at $\mathrm{m} / \mathrm{z} \quad 162-164$ that could correspond to C6 sugars.

The ${ }^{1} \mathrm{H}$ NMR (Figure 3) and ${ }^{13} \mathrm{C}$ NMR spectra (data not shown) seem to indicate the presence of sugars, the vast majority of signals protons resonate between 3.3-4.2 ppm and the majority of carbon signals resonate between 50-80 ppm. These signals are characteristic of $\mathrm{CH}(\mathrm{OR}), \mathrm{CH}(\mathrm{OH})$ and $\mathrm{CH}_{2}$ (OR) groups. There are also the signals around $100 \mathrm{ppm}$ carbon (carbon bonded to two oxygens) and signals to 170-180 ppm identified to a group $\mathrm{O}=\mathrm{CH}-\mathrm{O}-\mathrm{CH}_{3}$. We also note a set of proton signals (6.6-6.7 ppm) and carbon (130-140 ppm) characteristic of $\mathrm{C}=\mathrm{C}$ (alkene). These results suggest the presence of an aminoglycosidic compound.

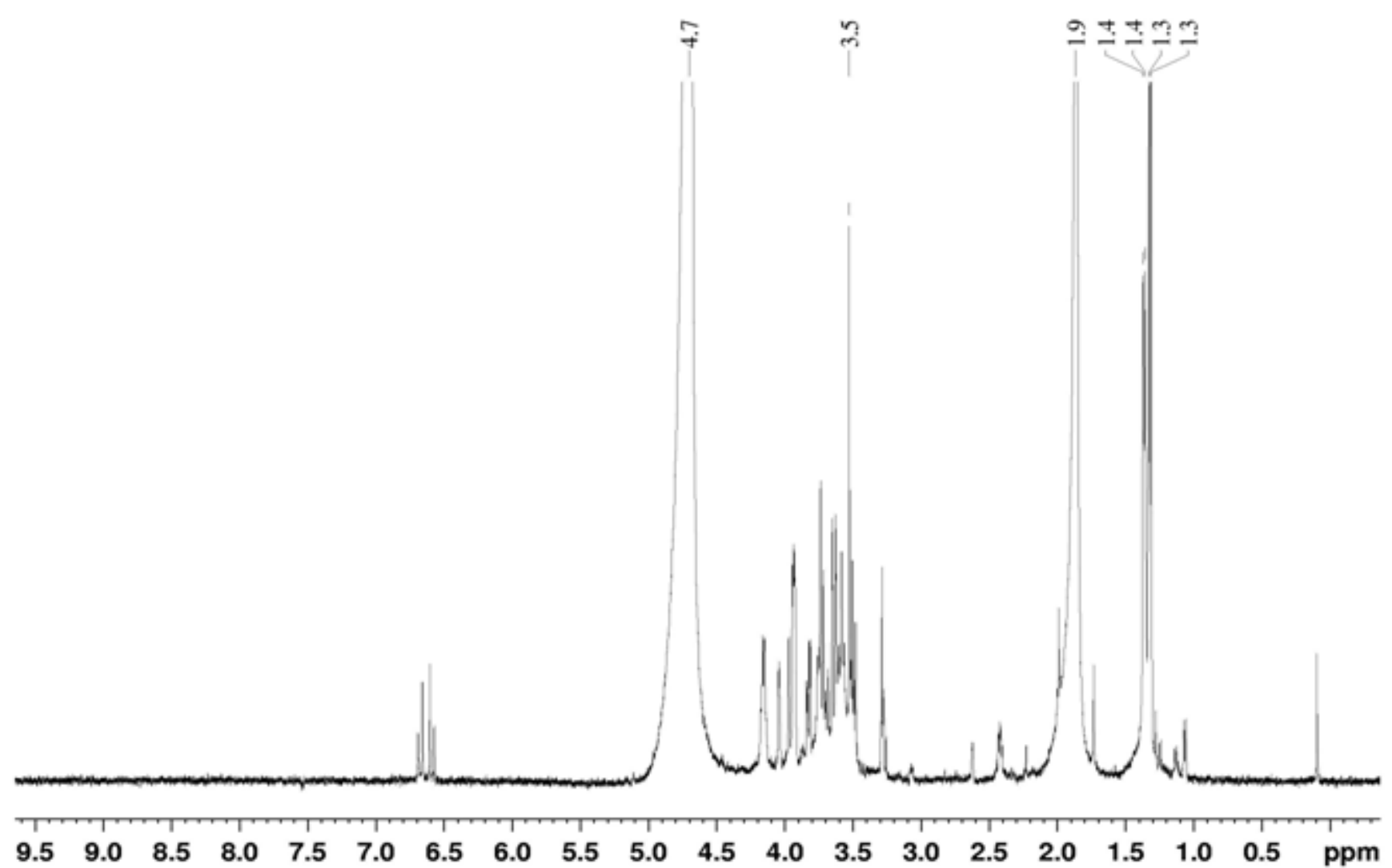

Figure 3. ${ }^{1} \mathrm{H}$ NMR of F1 compound produced by the strain AH97. 


\section{Fraction 2 (F2)}

Chromogenic reactions with napthoresorcinol- $\mathrm{H}_{2} \mathrm{SO}_{4}$ and ninhydrin were negative for F2 compound. UV-visible spectrum (data not shown) of the pure product F2 exhibited the maxima at 225 and $275 \mathrm{~nm}$ in methanol suggesting the presence of aromatic ring and the absence of polyenic structure.

Compound F2 was isolated as colorless oil, which had an IR absorption spectrum (data not shown): $3000-2800 \mathrm{~cm}^{-1}(\mathrm{C}$ $\mathrm{H}), 1800-1600 \mathrm{~cm}^{-1}$ (C-O), 1600-1580 $\mathrm{cm}^{-1}$ (aromatic ring) and $1300-1200 \mathrm{~cm}^{-1}$ (C-O). Molecular weight is 390 .

${ }^{1} \mathrm{H}$ NMR spectrum of pure fraction F2 (Fig. 4) showed some common main signals regions indicating the presence of methyl group at 0.94-0.98 ppm, ethyl group at 1.37-1.47 ppm,
$\mathrm{C}-\mathrm{H}$ at $1.70-1.71 \mathrm{ppm}, \mathrm{O}-\mathrm{CH}_{2}$ at $4.24-4.25 \mathrm{ppm}$ and aromatic ring at 7.64-7.75 ppm. Based on the spectral data and search in literature, fraction F2 was identified as dioctyl phthalate (Fig. 5), which has the same UV-visible and infrared spectrum, the same molecular weight and the same ${ }^{1} \mathrm{H}$ NMR spectrum.

Phthalate compounds are petrochemicals used as plasticisers or solvents in a variety of industrial products. Nevertheless, many phthalate derivatives have been isolated from terrestrial and marine organisms including plants $(16,17)$, marine algae (25), and fungal and bacterial culture broth, particularly those belonging to the genus Streptomyces. Our experiments were repeated 3 times at differentes periods to confirm that the dioctyl phthalate produced by strain AH97 was a natural product and not an impurity.

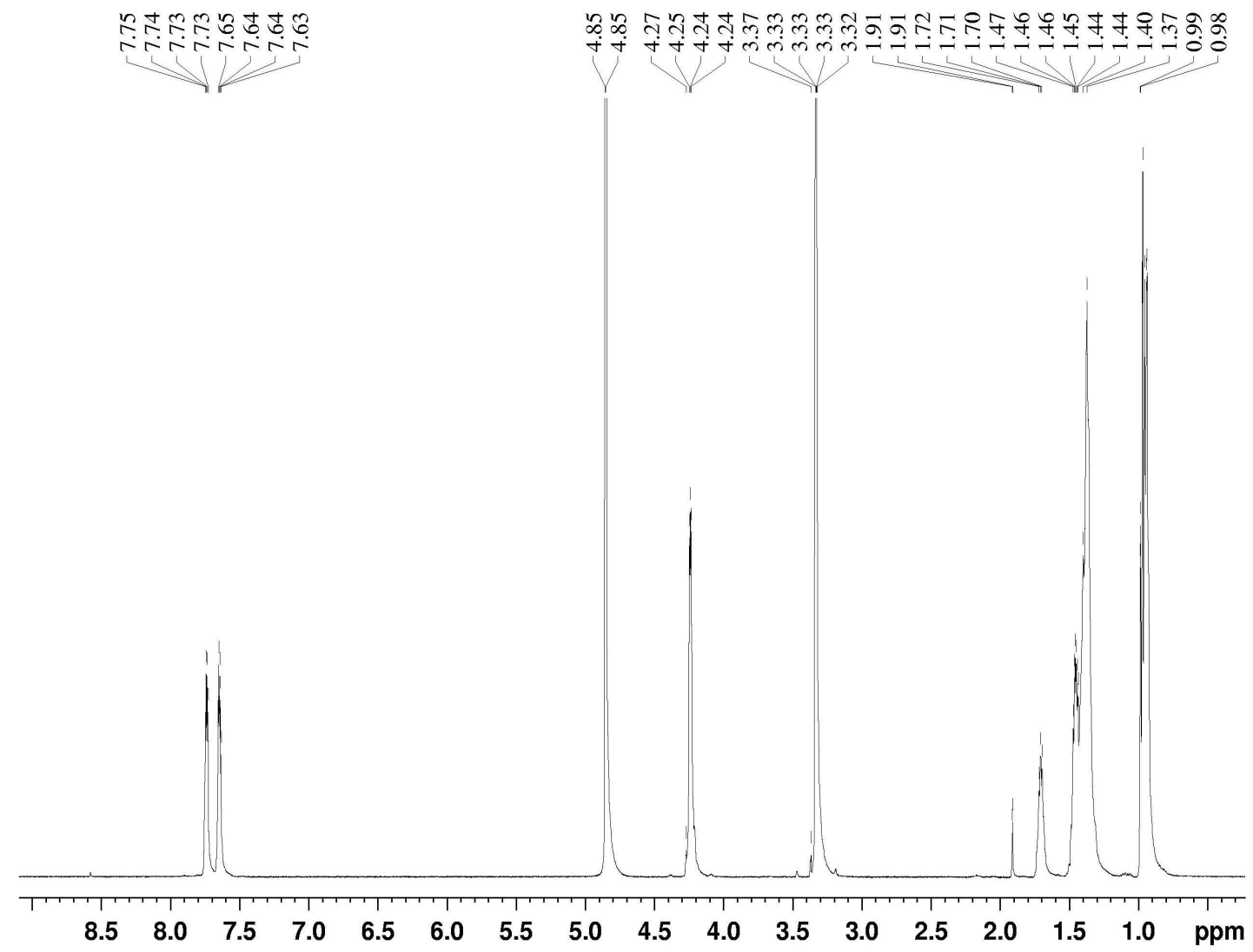

Figure 4. ${ }^{1} \mathrm{H}$ NMR of F2 compound produced by the strain AH97. 
<smiles>CCCCC(CC)COC(=O)c1ccccc1C(=O)OCC(CC)CCCC</smiles>

Figure 5. Chemical structure of the dioctyl phthalate.

\section{CONCLUSION}

A moderately halophilic actinomycete strain (AH97), isolated from saline Saharan soil, was identified by a polyphasic study to the genus Actinoalloteichus. Analysis of the $16 \mathrm{~S}$ rDNA sequence of this strain showed a similarity level at $98.4 \%$ with $A$. hymeniacidonis the most closely related which, in the other side, showed significant physiological characteristic differences. Strain AH97 showed an antibacterial and antifungal activity against broad spectrum of microorganisms.

Our results indicate that Actinoalloteichus sp. AH97 produced two bioactive compounds, F1 (hydrophilic) and F2 (hydrophobic). The comparison of their characteristics with those cited in the literature suggested that the product $(\mathrm{F} 1)$ is an aminoglycosidic compound and the product (F2) is the dioctyl phthalate. Further studies will be necessary to determine the structure of the F1 compound.

\section{REFERENCES}

1. Becker, B.; Lechevalier, M.P.; Gordon, R.E.; Lechevalier, H.A. (1964). Rapid differentiation between Nocardia and Streptomyces by paper chromatography of whole-cell hydrolysates. J. Appl. Microbiol., 12: 421423.

2. Berdy, J. (2005). Bioactive microbial metabolites. J. Antibiot., 58: 1-26.

3. Betina, V. (1973). Bioautography in paper and thin layer chromatography and its scope in the antibiotic field. J. Chromatogr., 78: 41-51.

4. Cai, Y. (2009). Classification and salt-tolerance of actinomycetes in the Qinghai lake water and lakeside saline soil. J. Sustain. Develop., 2: 107110 .

5. Felsenstein, J. (1985). Confidence limits on phylogenies: an approach using the bootstrap. Evolution., 39: 783-791.

6. Goodfellow, M. (1971). Numerical taxonomy of some nocardioform bacteria. J. Gen. Microbiol., 69: 33-90.

7. Gordon, R.E.; Barnett, D.A.; Handarhan, J.E.; Hor-Nay-Pang, C. (1974). Nocardia coeliaca, Nocardia autotrophica and the nocardin strains. Int. J. Syst. Bacteriol., 24: 54-63.

8. Gordon, R.E.; Barnett, D.A. (1977). Resistance to rifampicin and lysozyme of strains of some species of Mycobacterium and Nocardia as a taxonomic tool. Int. J. Syst. Bacteriol., 27: 176-178.

9. Jukes, T.H.; Cantor, C.R. (1969). Evolution of protein molecules. In: Munro, H.N. (ed). Mammalian protein metabolism, vol. 3. Academic Press, New York, pp. 21-132.

10. Kumar, S.; Tamura, K.; Nei, M. (2004). MEGA3: Integrated software for molecular evolutionary genetic analysis and sequence alignment. Brief. Bioinfo., 5: 150-163.

11. Kushner, D. J. (1993). Growth and nutrition of halophilic bacteria. In: Vreeland, L.I. (ed). The biology of halophilic bacteria, pp. 87-103.

12. Lamari, L.; Zitouni, A.; Boudjella, H.; Badji, B.; Sabaou, N.; Lebrihi, A.; Lefebvre, G.; Seguin, E. (2002). New dithiolopyrrolone antibiotics from Saccharothrix sp. Sa 233. I. Taxonomy, fermentation, isolation and biological activities. J. Antibiot., 55: 696-701.

13. Lazzarini, A.; Cavaletti, L.; Toppo, G.; Marinelli, F. (2001). Rare genera of actinomycetes as potential producers of new antibiotics. Ant. v. Leeuw., 78: 399-405.

14. Lechevalier, M.P.; Lechevalier, H.A. (1970). Composition of whole-cell hydrolysates as a criterion in the classification of aerobic actinomycetes. Int. J. Syst. Bacteriol., 20: 435-443. 
15. Lechevalier, M.P.; De Bièvre, C.; Lechevalier, H.A. (1977) Chemotaxonomy of aerobic actinomycetes: phospholipids composition. Biochem. Syst. Ecol., 5: 249-260.

16. Lee, D.S., (2000). Dibutyl phthalate, a glucosidase inhibitor from Streptomyces melanosporofaciens. J. Biosci. Bioeng., 89: 271-273.

17. Lee, K.H.; Kim, J.H.; Lim, D.S.; Kim C.S.; Kim C.H. (2000). Antileukaemic and antimutagenic effects of di(2.ethylhexyl) phthalate isolated from aloe linne. J. pharm. Pharmacol., 52: 593-598.

18. Liu, D.; Coloe, S.; Baird, R.; Pedersen, J. (2000). Rapid minipreparation of fungal DNA for PCR. J. Clinical. Microbiol., 38: 471.

19. Liu, Z.; Zhang, Y.; Yan, X. (1984). A new genus of the order Actinomycetales. Acta Microbiol. Sin., 24: 295-298.

20. Marchal, N.; Bourdon, J.L.; Richard, C.L. (1987). Milieux de culture pour l'isolement et l'identification biochimique des bactéries. Doin Press, Paris.

21. Minnikin, D.E.; Patel, P.V.; Alshamaony, L.; Goodfellow, M. (1977). Polar lipid composition in the classification of Nocardia and related bacteria. Int. J. Syst. Bacteriol., 27: 104-117.

22. Pfefferle, C.; Theobald, U.; Gürtler, H.; Fiedler, H-P. (2000). Improved secondary metabolite production in the genus Streptosporangium by optimization of the fermentation conditions. J. Biotechnol., 80: 135142.

23. Sabaou, N.; Boudjella, H.; Bennadji, A.; Mostefaoui, A.; Zitouni, A.; Lamari, L.; Bennadji, H., Lefebvre G.; Germain, P. (1998). Les sols des oasis du Sahara algérien, source d'actinomycetes rares producteurs d'antibiotiques. Sécheresse, 9: 147-153.

24. Saitou, N.; Nei, M. (1987). The neighbour-joining method: a new method for reconstructing phylogenetic trees. Mol. Biol. Evol., 4: 406425 .
25. Sastry, V.M.V.S.; Rao, G.R.K. (1995). Dioctyl phthalate and antibacterial compound from marine brown alga-Sargassum wightii. J. Appl. Phycology, 7: 185-186.

26. Sehgal, S.N.; Gibbons, N.E. (1960). Effect of some metal ions on the growth of Halobacterium cutirubrum. Can. J. Microbiol., 6: 165-169.

27. Shirling, E.B.; Gottlieb, D. (1966). Methods for characterization of Streptomyces species. Int. Syst. Bacteriol., 16: 3313-3340.

28. Singla, A. K.; Mayilraj, S.; Kudo, T.; Krishnamurthi, S.; Prasad, G. S.; Vohra, R. M.(2005). Actinoalloteichus spitiensis sp. nov., a novel Actinobacterium isolated from a cold desert of the Indian Himalayas. Int. J. Syst. Evol. Microbiol., 55: 2561-2564.

29. Tamura, T.; Zhiheng, L.; Yamei, Z.; Hanato, K. (2000). Actinoalloteichus cyanogriseus gen. nov., sp. nov. Int. J. Syst. Evol. Microbiol., 50: 1035-1040.

30. Thompson, J.D.; Higgins, D.G.; Gibson, T.J. (1994). CLUSTAL W: improving the sensitivity of progressive multiple sequence alignment through sequence weighing, position specific gap penalties and weight matrix choice. Nucl. Acids. Res., 22: 4673-4680.

31. Zhang, H.; Zheng, W.; Huang, J.; Luo, H.; Jin, Y.; Zhang, W.; Liu, Z.; Huang, Y. (2006). Actinoalloteichus hymeniacidonis sp. nov., an actinomycete isolated from the marine sponge Hymeniacidon perleve. Int. J. Syst. Evol. Microbiol., 56: 2309.

32. Zitouni, A.; Boudjella, H.; Mathieu, F.; Sabaou, N.; Lebrihi, A. (2004a). Mutactimycin PR, a new anthracycline antibiotic from Saccharothrix sp. Sa 103. Taxonomy, fermentation, isolation and biological activities. $J$. Antibiot., 57: 367-372.

33. Zitouni, A.; Lamari, L.; Boudjella, H.; Badji, B.; Sabaou, N.; Gaouar, A.; Mathieu, F.; Lebrihi, A. (2004b). Saccharothrix algeriensis sp. nov., isolated from Saharan soil. Int. J. Syst. Evol. Microbiol., 54: 1377-1381. 